\title{
Evidencia de circulación del virus de la hepatitis A, subgenotipo IA, en muestras ambientales en Antioquia, Colombia
}

\author{
Paula Andrea Báez¹, Carlos Mario Jaramillo', Lina Arismendi², Julio César Rendón¹, \\ Fabián Cortés-Mancera',3, Dioselina Peláez ${ }^{4}$, María Mercedes González ${ }^{5}$, \\ Francisco Molina², María Cristina Navas ${ }^{1}$ \\ 1 Grupo de Gastrohepatología, Facultad de Medicina, Universidad de Antioquia, Medellín, Colombia \\ 2 Grupo de Investigación en Gestión y Modelación Ambiental-GAIA, Facultad de Ingeniería, Universidad de \\ 3 Grupo de Investigación e Innovación Biomédica Gl²B, Instituto Tecnológico Metropolitano, Medellín, Colombia \\ 4 Grupo de Virología, Dirección Redes en Salud Pública, Instituto Nacional de Salud, Bogotá D.C, Colombia \\ 5 Facultad de Ciencias de la Salud, Universidad del Quindío, Armenia, Colombia
} Antioquia, Medellín, Colombia

Introducción. El virus de la hepatitis A (HAV) es un importante patógeno que se transmite por vía fecaloral. La epidemiología de la infección está directamente relacionada con el acceso de la población al agua potable y con la infraestructura de alcantarillado.

Objetivo. Determinar la presencia del HAV e identificar el genotipo en muestras de agua de abastecimiento y agua residual en ocho municipios, un corregimiento y una vereda del departamento de Antioquia, noroccidente de Colombia.

Materiales y métodos. Se hicieron tres muestreos seriados de diciembre de 2012 a abril de 2014 en la fuente principal de abastecimiento de los acueductos y en el principal vertimiento de aguas residuales de cada municipio. Las muestras se concentraron por filtración y ultrafiltración tangencial, y por las técnicas de polietilenglicol y floculación con leche descremada, respectivamente. A partir del ARN total de cada muestra, se amplificaron la región VP3-VP1 para la detección del genoma viral y la región VP1-2B para la genotipificación.

Resultados. El genoma del HAV se detectó en las fuentes de agua de abastecimiento de Puerto Berrío, Frontino y Nutibara, y en las muestras de aguas residuales provenientes de los municipios de Arboletes, Zaragoza y Venecia. Mediante el análisis de las secuencias se identificó el subgenotipo IA del virus.

Conclusión. Este estudio permitió detectar la presencia del HAV en 6,6 \% de las muestras de agua de abastecimiento y en $13,3 \%$ de las muestras de agua residual de los municipios en estudio. Se reporta por primera vez la circulación del subgenotipo IA en muestras ambientales en Antioquia.

Palabras clave: virus de la hepatitis, agua potable, aguas residuales, salud pública, genotipo, filogenia. doi: http://dx.doi.org/10.7705/biomedica.v36i0.2979

Evidence of the circulation of hepatitis A virus, subgenotype IA, in environmental samples from Antioquia, Colombia

Introduction: Hepatitis A virus (HAV) is an important pathogen, typically transmitted via the faecaloral route. The epidemiology of the infection is directly related to drinking water access and adequate disposal of sewage water.

Objective: To determine the presence and identify the genotype of HAV in environmental samples from eight municipalities and two villages in Antioquia, northwestern Colombia.

Materials and methods: Three serial samplings were done between December, 2012, and April, 2014. Water samples were obtained from drinking water plants prior to treatment, as well as from the main

\section{Contribución de los autores:}

Julio César Rendón: diseño del estudio

Paula Andrea Báez: muestreos y recolección de los datos, protocolos de concentración de partículas virales, ensayos moleculares y análisis filogenético, análisis e interpretación de los datos, discusión de resultados, redacción del manuscrito

Carlos Mario Jaramillo: muestreos y recolección de los datos, protocolos de concentración de partículas virales

Francisco Molina y María Cristina Navas: diseño del estudio, muestreos y recolección de los datos, análisis e interpretación de los datos, discusión de resultados, redacción del manuscrito

Lina Arismendi: muestreos y recolección de los datos

María Mercedes González y Dioselina Peláez: protocolos de concentración de partículas virales

Fabián Cortés-Mancera: análisis e interpretación de los datos, discusión de resultados 
reserve of wastewater in each municipality included in the study. Viral concentrations for the two types of sample sources were determined by filtration/tangential ultrafiltration and polyethyleneglycol plus flocculation with skimmed milk, respectively. Total ARN was subsequently obtained from each sample and the VP3-VP1 region amplified for detection of the viral genome. The genotype was determined by amplification of the VP1-2B region.

Results: The HAV genome was detected in samples from drinking water plants at Puerto Berrío, Frontino and Nutibara, and in wastewater samples from the municipalities of Arboletes, Zaragoza and Venecia. HAV subgenotype IA was identified using phylogenetic analysis.

Conclusion: In this study, HAV was identified in $6.6 \%$ of the samples from drinking water plants and $13.3 \%$ of wastewater samples. This is the first report of HAV subgenotype IA circulating in environmental samples from Antioquia.

Key words: Hepatitis viruses, drinking water, waste water, public health, genotype, phylogeny. doi: http://dx.doi.org/10.7705/biomedica.v36i0.2979

El virus de la hepatitis A (HAV) pertenece a la familia Picornaviridae, género Hepatovirus. El genoma viral está compuesto por ARN de cadena sencilla, de polaridad positiva y de $7,5 \mathrm{~kb}$, aproximadamente (1). La partícula viral es de simetría icosaédrica y no posee envoltura lipídica (2), aunque recientemente se ha descrito una forma transitoria de la partícula embebida en una bicapa lipídica que le permitiría evadir la neutralización mediada por anticuerpos, facilitando su tránsito entre el hepatocito y el sistema biliar (3).

EI HAV se encuentra clasificado en seis genotipos (I-VI) y seis subgenotipos (IA, IB, IIA, IIB, IIIA y IIIB), con un porcentaje de variabilidad de 15 y $7 \%$, respectivamente (4-8). Los genotipos I, II y III se han aislado principalmente de humanos $(5,9)$ y, los genotipos IV, V y VI, de primates $(4,6,10,11)$. El genotipo I se encuentra distribuido a nivel mundial; el subgenotipo IA es prevalente en Europa occidental y en América $(5,12)$, y comprende la mayoría de cepas estudiadas aisladas de humanos, así como de muestras ambientales (13-16).

EI HAV se transmite principalmente por vía fecaloral mediante el consumo de agua o alimentos contaminados $(8,17)$. En el medioambiente, la partícula viral conserva su capacidad infecciosa durante periodos prolongados (8), lo cual facilita la dispersión del virus en fuentes de agua.

La Organización Mundial de la Salud (OMS) estima que en el mundo se presentan, aproximadamente, 1,4 millones de infecciones al año, aunque la tasa

\footnotetext{
Correspondencia:

María Cristina Navas, Grupo de Gastrohepatología, Universidad de Antioquia, Universidad de Antioquia, Calle $70 \mathrm{~N}^{\circ} 52-21$, Medellín, Colombia

Teléfono: (574) 219 6573; fax: (574) 2196565

maria.navas@udea.edu.co

Recibido: 17/07/15; aceptado: 16/02/16
}

de infección es probablemente 10 veces mayor si se consideran los casos sin ictericia y los casos asintomáticos $(18,19)$. Según un reciente informe del peso de las enfermedades causadas por alimentos contaminados, el HAV fue el agente en más de 13 millones de casos de hepatitis viral y el causante de más de 27.000 muertes en 2010 en el mundo (20). La situación epidemiológica deAmérica Latina es difícil de estimar por el subregistro, y por la diferencia en los patrones epidemiológicos y en los programas de vigilancia entre los países. Esta región presentaba un patrón de alta endemia hasta la década de los 90, pero gracias a las políticas de salud pública, el acceso al agua potable, el sistema de alcantarillado y las prácticas de higiene personal, dicho patrón cambió a endemia intermedia $(19,21)$, el cual se documentó en la mayoría de los países latinoamericanos, incluido Colombia (21).

La introducción de la vacuna en países de la región, como Argentina, Brasil y Chile, ha tenido un gran impacto en la morbimortalidad de la infección por HAV (19,22-24). En el caso de Argentina, la vacuna se introdujo en el 2005 y desde el 2006 se ha podido observar una reducción de $88,1 \%$ en la incidencia de la infección por HAV, tanto así que desde marzo de 2007 no se registran casos de falla hepática aguda ni trasplantes de hígado en pacientes con hepatitis $A(22,23)$. En Colombia, el programa de vacunación contra el HAV se inició en el 2013; la vacuna se administra en una dosis única a los doce meses de edad (25).

Según los datos del Sistema Nacional de Vigilancia en Salud Pública (Sivigila) de Colombia, a partir del 2008 se ha observado un descenso significativo a nivel nacional de los casos de hepatitis $A$, probablemente gracias a mejoras en los sistemas de saneamiento y disposición de residuos $(8,26)$. En ese año se notificaron 8.981 casos de hepatitis A en el territorio nacional, en el 2009, 6.708 casos, 
en el 2010, 5.064 casos, en el 2011, 5.573, en el $2012,5.339$ casos, en el 2013, 4.807 casos y en el 2014, 2.901 casos. En el 2014, 390 de los casos se reportaron en Antioquia, lo cual lo ubica como el departamento con el mayor número de casos (8,26-28).

La identificación y la caracterización del virus en la fuente principal de abastecimiento de los acueductos y en las aguas residuales aportan información importante sobre su circulación en la comunidad y determina el riesgo de brotes en el caso de las poblaciones que no cuentan con planta de potabilización. Según un estudio realizado por el Instituto Nacional de Salud en muestras de agua para consumo humano durante brotes de hepatitis A, entre el 2008 y el 2013, el genoma del HAV se detectó en $38,7 \%$ de las muestras analizadas. Las muestras de agua se recolectaron en 52 municipios del territorio nacional y, de ellas, 23,6\% correspondía a muestras de agua tratada y $64,7 \%$ a agua no tratada (29).

El presente estudio tuvo como fin determinar la presencia del HAV e identificar el genotipo en muestras de la fuente principal de abastecimiento de los acueductos y en el agua residual de nueve municipios y un corregimiento en las nueve subregiones del departamento de Antioquia.

\section{Materiales y métodos}

\section{Tipo de estudio}

Se hizo un estudio de tipo descriptivo, transversal, en las fuentes de abastecimiento del acueducto y en los sitios finales de descarga de aguas residuales de ocho cabeceras municipales, un corregimiento y una vereda del departamento de Antioquia.

\section{Selección de municipios}

Los municipios del estudio corresponden a aquellos de cada subregión del departamento con la mayor tasa de incidencia de hepatitis $A$ entre 2006 y 2009, según los indicadores básicos de la Dirección Seccional de Salud de Antioquia (30) (cuadro1).

Se incluyeron ocho municipios (Arboletes, Cisneros, Frontino, Granada, Puerto Berrío, San Pedro de los Milagros, Venecia y Zaragoza), un corregimiento (Nutibara en Frontino) y una vereda (San Andrés en Girardota), ubicados en las nueve subregiones del departamento (figura 1). En el municipio de Girardota se acordó obtener las muestras en la vereda San Andrés, dado que la cabecera municipal es abastecida por el acueducto de Medellín. Además de la cabecera municipal, en el municipio de Frontino también se incluyó el corregimiento de Nutibara, pues según la Secretaría de Salud de Frontino, la mayoría de casos notificados provienen de allí (31). El proyecto fue aprobado por las autoridades locales de cada población y por el Comité de Ética de la Facultad de Medicina de la Universidad de Antioquia.

\section{Recolección de muestras ambientales y condiciones de pluviosidad}

Se hicieron tres muestreos seriados desde diciembre de 2012 hasta abril de 2014, y se consideraron las condiciones de pluviosidad a lo largo del

Cuadro 1. Incidencia promedio de la hepatitis A en el periodo 2006 a 2009 y sistemas de tratamiento de aguas de los municipios incluidos en el estudio

\begin{tabular}{|c|c|c|c|c|c|}
\hline $\begin{array}{l}\text { Subregión del } \\
\text { departamento } \\
\text { de Antioquia }\end{array}$ & Municipio & $\begin{array}{c}\text { Población } \\
\text { municipal } \\
2009 \text { (32) }\end{array}$ & $\begin{array}{c}\text { Promedio de la incidencia } \\
\text { de hepatitis A } \\
\text { (2006 a 2009, tasa por } \\
100.000 \text { habitantes) (32) }\end{array}$ & PTAP & PTAR \\
\hline Occidente & $\begin{array}{l}\text { Frontino } \\
\text { (corregimiento Nutibara) }\end{array}$ & $\begin{array}{r}18.583 \\
887^{*}\end{array}$ & $\begin{array}{l}77,6 \\
\text { Sin dato }\end{array}$ & $\begin{array}{l}\text { Sí } \\
\text { No }\end{array}$ & $\begin{array}{l}\text { Laguna de oxidación } \\
\text { No }\end{array}$ \\
\hline Norte & San Pedro de los Milagros & 23.855 & 73,5 & Sí & Sí \\
\hline Oriente & Granada & 9.818 & 66,2 & Sí & Sí \\
\hline Suroeste & Venecia & 13.365 & 39,1 & Sí & Sí \\
\hline Urabá & Arboletes & 34.293 & 37,6 & Sí & Laguna de oxidación \\
\hline Valle de Aburrá & $\begin{array}{l}\text { Girardota } \\
\text { (vereda San Andrés) }\end{array}$ & 47.055 & 26,8 & No & Sí \\
\hline Bajo Cauca & Zaragoza & 28.477 & 25,1 & Sí & No \\
\hline Magdalena Medio & Puerto Berrío & 42.038 & 21,4 & Sí & Laguna de oxidación \\
\hline Nordeste & Cisneros & 9.439 & 10,4 & No & No \\
\hline
\end{tabular}

PTAP: punto de entrada a la planta de potabilización; PTAR: planta de tratamiento de agua residual *Según el censo de 2005 
año. En el cuadro 2 se presentan los datos de las precipitaciones registrados por el Instituto de Hidrología, Meteorología y Estudios Ambientales

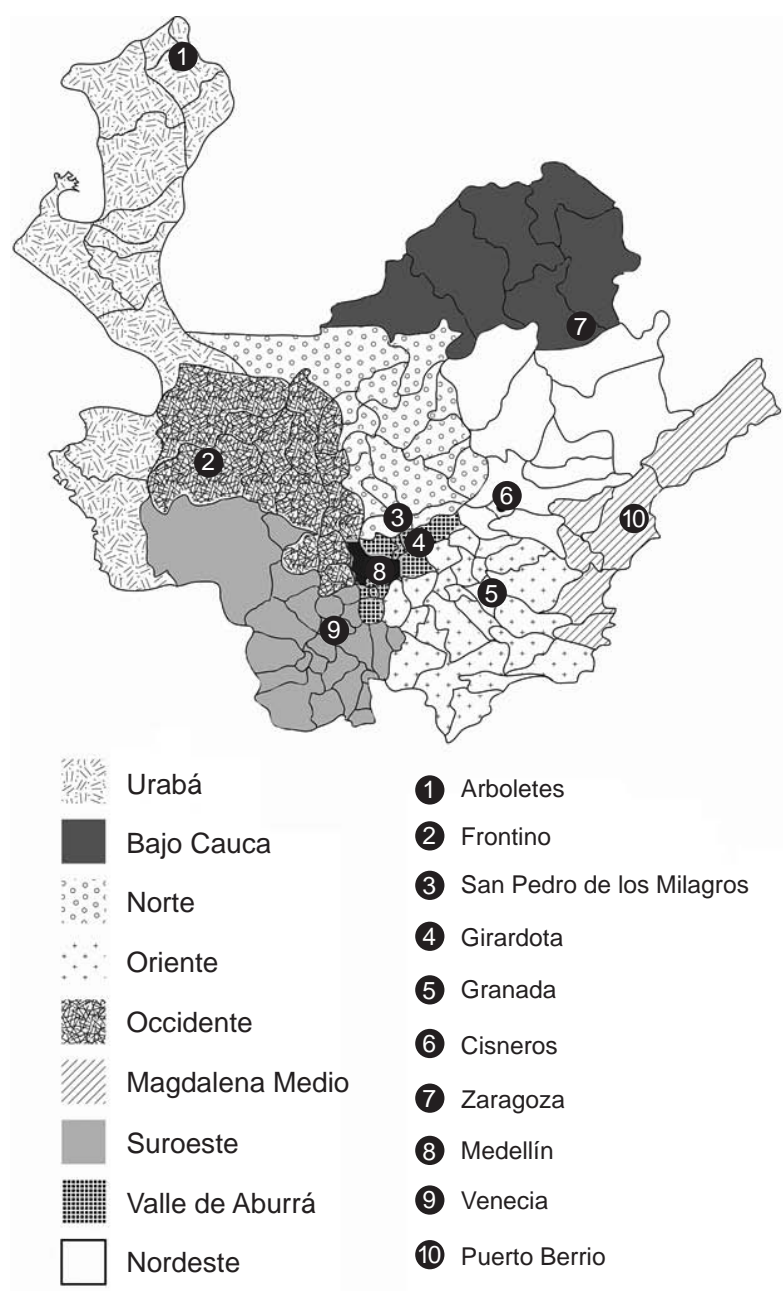

Figura 1. Subregiones del departamento de Antioquia y localización de los municipios incluidos en el estudio
(IDEAM) y los datos cualitativos suministrados por el personal del acueducto de cada población durante los muestreos. Durante el trabajo de campo, se obtuvo información de la infraestructura de las plantas de tratamiento de agua potable y de las plantas de aguas residuales existentes.

El primer muestreo se hizo entre diciembre de 2012 y mayo de 2013, periodo durante el cual se presentaron lloviznas leves y aisladas, en contraste con las fuertes y constantes precipitaciones que ocurrieron durante el segundo muestreo llevado a cabo entre septiembre y noviembre de 2013. Durante el tercer muestreo, entre diciembre de 2013 y abril de 2014, se presentaron lluvias leves y esporádicas.

La muestra de agua de la fuente principal de abastecimiento de los acueductos se tomó en el punto de entrada a la planta de potabilización, antes de someterse a cualquier tipo de tratamiento. En las poblaciones que no disponían de dicha planta, la muestra se recolectó antes del punto de distribución a las viviendas. En ambas circunstancias se recolectaron cinco litros de agua por muestra.

Las muestras de agua residual se obtuvieron en el punto de entrada a las plantas de tratamiento de agua residual, antes de iniciar el tratamiento. En los municipios que no poseían la infraestructura para el tratamiento de aguas residuales, la muestra se recolectó en el sitio final de descarga del efluente cloacal. En ambos casos se tomaron dos litros de agua en cada muestra.

Las muestras se recolectaron en recipientes plásticos limpios y nuevos, que se marcaron, se sellaron y se transportaron en cadena de frío hasta el Laboratorio de Gastrohepatología de la

Cuadro 2. Precipitación pluvial en los municipios durante el periodo de estudio en valores totales diarios durante la semana de muestreo*

\begin{tabular}{lccc}
\hline \multicolumn{4}{c}{ Precipitación durante la semana del muestreo (en mm) } \\
\hline Municipio & Primer muestreo & Segundo muestreo & Tercer muestreo \\
\hline Girardota (vereda San Andrés) & 53 & 23 & 41 \\
Zaragoza & 72 & 123 & 5 \\
Frontino & 90 & 33 & 29 \\
Granada & 161 & 132 & 66 \\
Arboletes & 2,1 & 67,4 & Lloviznas leves \\
Puerto Berrío & 171 & Fuertes precipitaciones & Lloviznas leves \\
Venecia & Lluvias moderadas & Fuertes precipitaciones & Lloviznas leves \\
San Pedro de los Milagros & Lluvias moderadas & Fuertes precipitaciones & Lloviznas leves \\
Cisneros & Lluvias moderadas & Fuertes precipitaciones & Lloviznas leves \\
\hline
\end{tabular}

*Los datos suministrados por el Instituto de Hidrología, Meteorología y Estudios Ambientales (IDEAM) se muestran en valores cuantitativos y los datos suministrados por los funcionarios de los acueductos, mediante descripciones cualitativas. 
Universidad de Antioquia, donde se almacenaron a $4{ }^{\circ} \mathrm{C}$ durante 24 horas como máximo, antes de proceder con el protocolo de concentración.

\section{Concentración de partículas virales}

Las muestras de agua de suministro de los acueductos se concentraron empleando la metodología de filtración y ultrafiltración tangencial descrita previamente por Peláez, et al. (33), con filtros de $0,8,0,45$ y $0,22 \mu \mathrm{m}$. Las muestras de agua residual del primer muestreo se concentraron mediante la técnica de polietilenglicol descrita por Sobsey (34) con las modificaciones introducidas en el protocolo por González, et al. (35). Para el segundo y el tercer muestreos, se utilizaron las técnicas de polietilenglicol descritas por Martínez, et al. (36), y la de floculación con leche descremada descrita por Calgua, et al. $(37,38)$. Los productos de la concentración viral se almacenaron a $-70^{\circ} \mathrm{C}$ hasta su posterior análisis.

\section{Extracción de ARN y reacción en cadena de la polimerasa con transcripción inversa}

La extracción de ARN viral se hizo en $140 \mu$ del producto de la concentración viral utilizando un estuche comercial (QIAamp viral RNA mini kit ${ }^{\circledR}$, Qiagen, Alemania). Se hizo una primera reacción en cadena de la polimerasa (PCR) con transcripción inversa para amplificar un fragmento de $192 \mathrm{pb}$ de la región VP3-VP1 del genoma viral según la descripción de Schwab, et al. (39). Este es el protocolo de referencia del Laboratorio de Virología del Instituto Nacional de Salud para el diagnóstico y para muestras ambientales.

La reacción con transcripción inversa se hizo con un volumen final de $20 \mu \mathrm{l}$. Se utilizaron los iniciadores Random Primers 1,5 $\mathrm{mM}^{\mathrm{TM}}$ (Invitrogen, Life Technologies, USA) y Super Script III 200 U/ $\mu \mathrm{I}^{\mathrm{TM}}$ (Invitrogen $^{\mathrm{TM}}$, Life Technologies, USA), y $10 \mu \mathrm{l}$ del ARN. La síntesis de ADN complementario se hizo a $55^{\circ} \mathrm{C}$ durante 60 minutos y la reacción se inactivó a $70^{\circ} \mathrm{C}$ durante 15 minutos.

Posteriormente, la amplificación se hizo con los oligonucleótidos HAV-L (nucleótidos 2019-2038, 5'-CAGCACATCAGAAAGGTGAG-3') y HAV-R (nucleótidos 2192-2210, 5'-CTCCAGAATCATCTC CAAC-3') (39) y $5 \mu \mathrm{l}$ de ADN complementario. El protocolo consistió en la desnaturalización inicial a $95{ }^{\circ} \mathrm{C}$ durante tres minutos, seguida de 35 ciclos de desnaturalización a $94^{\circ} \mathrm{C}$ durante 30 segundos; hibridación a $52{ }^{\circ} \mathrm{C}$ durante 35 segundos; una extensión a $72{ }^{\circ} \mathrm{C}$ durante 35 segundos, y una extensión final a $72{ }^{\circ} \mathrm{C}$ durante siete minutos.
Las muestras positivas para la detección del genoma del VHA se sometieron a una segunda PCR con transcripción inversa anidada, según lo descrito por Mitsui, et al. (40), la cual amplifica un fragmento de 522 pb de la región VP1-2A para la identificación del genotipo. La síntesis de ADN complementario se hizo utilizando el oligonucleótido HA022 (nucleótidos 3414-3435, 5'-TTRTCATCY TTCATTTCTGTCC-3') en las mismas condiciones descritas previamente para la PCR con transcripción inversa empleada en la detección.

La primera ronda de amplificación se hizo con los oligonucleótidos HA022 y HA021 (nucleótidos 28882912, 5'-ATTGCAAATTAYAAYCAYTCTGATG-3') y $10 \mu \mathrm{l}$ de ADN complementario. El protocolo consistió en la desnaturalización inicial a $94^{\circ} \mathrm{C}$ durante dos minutos, seguida de 35 ciclos de desnaturalización a $94{ }^{\circ} \mathrm{C}$ durante 30 segundos, hibridación a $52{ }^{\circ} \mathrm{C}$ durante 30 segundos; una extensión a $72{ }^{\circ} \mathrm{C}$ durante 60 segundos, y una extensión final a $72{ }^{\circ} \mathrm{C}$ durante siete minutos.

Se procedió de manera similar en la segunda ronda de amplificación con los oligonucleótidos HA023 (nucleótidos 2903-2922, 5'-CATTCTGATGAATA YTTGTC-3') y HA024 (nucleótidos 3404-3424, 5'-CATTTCTGTCCATTTYTCATC-3'). El protocolo de amplificación fue de 25 ciclos en las mismas condiciones de la primera ronda.

Se emplearon $5 \mathrm{U} / \mu \mathrm{l}$ de la enzima GoTaq Flexi DNA Polymerase ${ }^{\circledR}$ (GoTaq, Promega Corporation, USA) para todos los ensayos de amplificación. Los ensayos de PCR con transcripción inversa se hicieron por duplicado con el ARN obtenido de cada muestra en una dilución de 1:10, para controlar la posible presencia de inhibidores de la PCR en las muestras analizadas.

Los productos de la PCR se visualizaron en gel de agarosa al $2 \%$ en solución tampón TAE 1X, teñido con bromuro de etidio $(0,1 \mathrm{mg} / \mathrm{ml})$. Como control positivo se utilizó una muestra de suero de un paciente con resultado positivo para la infección por HAV, la cual fue donada por el Instituto Nacional de Salud.

\section{Análisis filogenético}

Se secuenció el producto de amplificación de la región VP1-2A (522 pb) (Macrogen Inc., Corea). En la base de datos de la filogenia de HAV, se incluyeron únicamente secuencias del genoma completo del VHA, con caracterización del genotipo y el subgenotipo. Se depuraron las secuencias similares entre sí mediante el uso de un análisis de 
distancias (Pairwise Distance Test). El alineamiento y la edición de las secuencias resultantes se hicieron en el programa BioEdit 7.1.11, y la filogenia se elaboró en el programa MEGA 5.2 con el método de máxima verosimilitud y el modelo evolutivo Tamura de tres parámetros más sitios invariantes $(\mathrm{T} 92+\mathrm{I})$, escogido con base en el mejor criterio de información bayesiano (BIC). Se utilizaron 1.000 réplicas de bootstrap.

\section{Resultados}

Durante el primer muestreo, el genoma del HAV se detectó en las muestras de agua residual recolectadas en los municipios de Venecia, Arboletes y Zaragoza (30\%, 3/10), así como en las muestras de agua de la fuente principal de suministro de los acueductos del corregimiento de Nutibara y el municipio de Puerto Berrío $(20 \%, 2 / 10)$. En el segundo muestreo, el genoma del HAV se detectó únicamente en la muestra de agua residual recolectada en la cabecera municipal del municipio de Frontino (10\%, 1/10). Todas las muestras obtenidas durante el tercer muestreo fueron negativas para la detección del genoma viral. En total, el genoma del HAV se detectó en $13,3 \%(4 / 30)$ de las muestras de agua residual y en $6,6 \%(2 / 30)$ de las muestras del agua de suministro de los acueductos (cuadro 3 ), es decir, $10 \%(6 / 60)$ del total de muestras obtenidas durante el periodo de estudio.

Mediante la PCR con transcripción inversa anidada fue posible amplificar la región VP1-2A con fines de genotipificación en cuatro de las seis muestras positivas. La base de datos para la construcción de la filogenia del HAV se conformó con las secuencias del genoma completo de los subgenotipos IA, IB, IIA, IIB, IIIA y IIIB disponibles en GenBank. Además, se incluyó una secuencia del genotipo $\mathrm{V}$ como raíz del árbol filogenético. El subgenotipo IA del HAV se asignó a las muestras de estudio con un soporte de rama de 97 \% según el árbol filogenético resultante (figura 2). Las secuencias de estudio se concentraron en dos grupos diferentes, uno de ellos conformado por secuencias de Uruguay, Alemania y Argentina, y el otro conformado por secuencias de Japón, China y México (figura 2).

\section{Discusión}

Se sabe que la contaminación del agua para consumo es uno de los principales vehículos de transmisión de microorganismos patógenos al humano. La vigilancia de la calidad del agua para consumo humano y el apoyo durante los brotes de hepatitis A son dos estrategias importantes en la prevención de la transmisión de virus entéricos, como es el caso del virus de la hepatitis $A$.

En Colombia, las características de calidad del agua potable se encuentran reglamentadas desde el 2007 (41,42). En dicha reglamentación se utilizan como indicadores de contaminación microbiana las pruebas de coliformes totales y Escherichia coli y, además, se requiere del análisis de los parásitos Giardia spp. y Crypstosporidium spp. La evaluación de los virus no está reglamentada, pero según el artículo 12 de la Resolución 2115 (42), con base en el mapa de riesgos se debe verificar la presencia de otros microorganismos patógenos en el agua, así como la viabilidad de establecer otros indicadores. Por lo tanto, en los municipios donde se presenta el riesgo de contaminación por HAV, se debe evaluar la posibilidad de integrar su detección como indicador de la calidad del agua potable.

Cuadro 3. Detección del genoma del VHA en muestras de agua residual y agua de abastecimiento durante el periodo de estudio

\begin{tabular}{|c|c|c|c|c|c|c|}
\hline \multirow[t]{2}{*}{ Municipio } & \multicolumn{2}{|c|}{$\begin{array}{l}\text { Primer muestreo } \\
\text { Diciembre de } 2012 \\
\text { a mayo de } 2013\end{array}$} & \multicolumn{2}{|c|}{$\begin{array}{l}\text { Segundo muestreo } \\
\text { Septiembre a } \\
\text { noviembre de } 2013\end{array}$} & \multicolumn{2}{|c|}{$\begin{array}{l}\text { Tercer muestreo } \\
\text { Diciembre de } 2013 \\
\text { a abril de } 2014\end{array}$} \\
\hline & Residual & Abastecimiento & Residual & Abastecimiento & Residual & Abastecimiento \\
\hline Girardota (vereda San Andrés) & - & - & - & - & - & - \\
\hline San Pedro de los Milagros & - & - & - & - & - & - \\
\hline Venecia & + & - & - & - & - & - \\
\hline Granada & - & - & - & - & - & - \\
\hline Cisneros & - & - & - & - & - & - \\
\hline Arboletes & + & - & - & - & - & - \\
\hline Zaragoza & + & - & - & - & - & - \\
\hline Frontino & - & - & + & - & - & - \\
\hline Corregimiento Nutibara & - & + & - & - & - & - \\
\hline Puerto Berrío & - & + & - & - & - & - \\
\hline
\end{tabular}




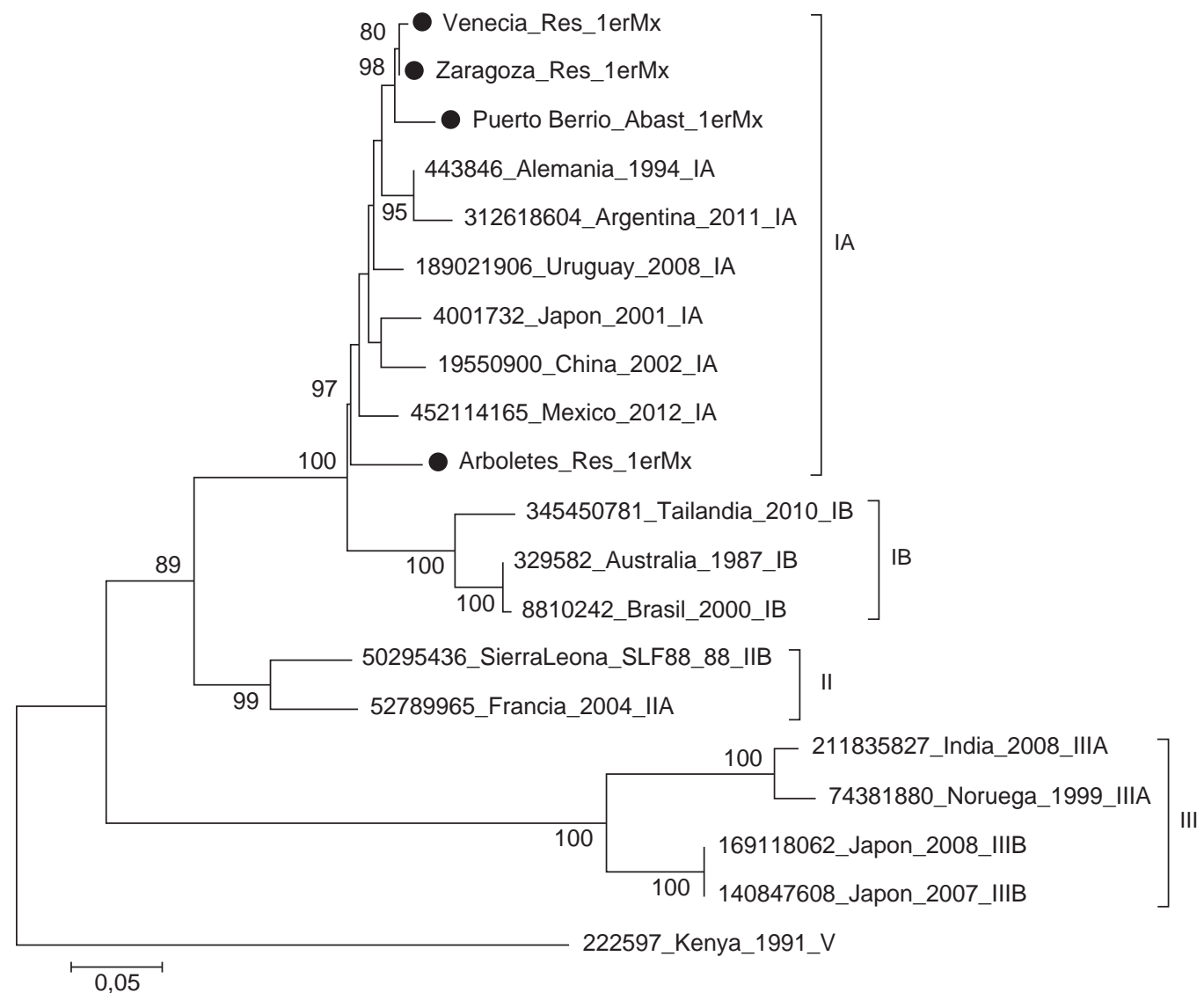

Figura 2. Filogenia del virus de la hepatitis A elaborada a partir de la amplificación de un fragmento de 522 pb de la región VP1-2A. El árbol filogenético se obtuvo con el programa Mega 5.2 empleando el método de máxima verosimilitud en el marco del modelo de Tamura de tres parámetros más sitios invariantes $(T 92+\mathrm{l})$, seleccionado con base en el criterio de información bayesiano. Las secuencias de estudio se indican con un círculo negro y el clado del subgenotipo IA se identifica en color gris. Se muestran los valores de bootstrap mayores de $70 \%$ después de 1.000 réplicas. Las secuencias se identifican con el número de acceso a GenBank, seguido del país, el año de aislamiento y el genotipo. Las denominadas Venecia_Res_1erMx, Zaragoza_Res_1erMx y Arboletes Res 1erMx, corresponden a las muestras de agua residual recolectadas durante el primer muestreo en los municipios de Venecia, Zaragoza y Arboletes. La denominada Puerto Berrío_Abast_1erMx corresponde a la muestra de agua de suministro del acueducto del municipio en mención, recolectada durante el primer muestreo.

La Resolución 2115 de 2007 (42) establece el índice de calidad del agua para consumo humano como un instrumento básico para garantizar la calidad del agua potable. Este índice se calcula a partir de la determinación de 20 parámetros fisicoquímicos (con un cumplimiento mínimo de 60 puntos sobre 100) y dos parámetros microbiológicos (cumplimiento mínimo de 40 puntos sobre 100).

En el 2013 este índice fue de 26,57 en el país, un valor que se considera indicativo de riesgo medio; al discriminar por zona urbana (cabeceras de los municipios), el índice fue de 11,28, lo que corresponde a riesgo bajo, mientras que la zona rural presentó un índice de 52,12, el cual se considera de alto riesgo. Estos datos indican un avance en cuanto a la calidad del agua en las cabeceras municipales (zona urbana), según lo registrado entre 2007 y 2013; sin embargo, el mismo índice en las poblaciones rurales se ha mantenido en valores indicativos de riesgo alto. En este sentido, las muestras de agua para consumo humano obtenidas en el 2013 en la zona rural demostraron que solo $18 \%$ de la población rural tenía acceso al agua potable, $15,1 \%$ a agua tratada con riesgo bajo o medio (agua segura), y $66,9 \%$ de la población consumía agua no tratada obtenida a través de un sistema de acueducto $(43,6 \%)$ o adquirida directamente de la quebrada o el río (23,3\%) (43).

La situación del departamento de Antioquia difiere un tanto de lo observado en las cifras consolidadas del país. Este departamento cuenta con 125 municipios y una población de 6’299.990 
habitantes, $77,8 \%$ en la zona urbana y $22,2 \%$ en la zona rural. En 2013 este indicador fue de 9,41 para el departamento: 8,94 en la zona rural y 9,4 en la zona urbana (44). Sin embargo, vale la pena anotar que $82,1 \%$ de la población del departamento tiene acceso al agua potable, 4,83\% a agua tratada (con riesgo mínimo y medio), y $2,96 \%$ a agua no tratada.

El análisis por municipio demostró que en el 2013, Cisneros tenía un índice de calidad del agua para consumo humano de 86,17, mientras que en Zaragoza y Puerto Berrío se registraron valores de riesgo medio: 30,75 y 14,15, respectivamente (43).

Los resultados del presente estudio complementan la información de la vigilancia de la calidad del agua, y demostraron la circulación del HAV en $6,6 \%(2 / 30)$ de las muestras de agua de la fuente de suministro de los acueductos recolectadas en la quebrada La Golondrina, corregimiento de Nutibara, y en el río Magdalena, municipio de Puerto Berrío, así como en 13,3\% (4/30) de las muestras de agua residual de los municipios de Arboletes, Venecia, Frontino y Zaragoza. Vale la pena resaltar que Puerto Berrío cuenta con planta de potabilización, mientras que el corregimiento de Nutibara no tiene ningún tipo de infraestructura para la potabilización de agua de suministro del acueducto local, lo que pone en evidencia el riesgo de infección por HAV para la comunidad.

Los procesos y operaciones unitarias de potabilización del agua deben garantizar una eficiencia de cuatro logaritmos $(99,99 \%)$ en la remoción de patógenos y virus (44), eficiencia que normalmente se logra utilizando los procesos convencionales de coagulación, floculación, sedimentación, filtración y desinfección (44). En la desinfección, generalmente se utilizan la cloración, la ozonización o la radiación ultravioleta, las cuales son confiables para la eliminación de virus y patógenos en cuatro logaritmos (4446). Sin embargo, se deben resaltar dos hechos importantes: primero, es necesario contar con un proceso de desinfección residual para prevenir nuevas contaminaciones en la red de distribución, y solo la cloración cumple con esta condición; por lo tanto, cuando se utilizan las técnicas de ozonización o radiación ultravioleta, debe haber un proceso posterior de cloración para garantizar la calidad del agua en la red de acueducto.

El segundo elemento para garantizar la calidad del agua potable son los procesos previos (coagulación, floculación, sedimentación, filtración), los cuales garantizan eficiencias de dos logaritmos (99\%) (42); por lo tanto, el lograr 99,99\% de eficiencia en la remoción de virus y agentes patógenos depende del proceso de desinfección, y cualquier deficiencia en dicho proceso genera el riesgo de contaminación microbiológica y viral para la población. Por consiguiente, si existe evidencia o sospecha de la presencia del VHA en la fuente de abastecimiento (río o quebrada) de la planta de agua potable, se debe adelantar el proceso de desinfección con el mayor rigor posible.

En poblaciones donde no exista planta de tratamiento, es necesario tomar medidas preventivas como la cloración de emergencia, la desinfección por temperatura del agua para consumo humano y la educación de la población. Este es el caso del corregimiento de Nutibara, que no cuenta con planta de potabilización y donde se demostró la presencia del HAV durante el periodo de estudio en la quebrada que abastece el acueducto de este asentamiento (cuadro 2). Teniendo en cuenta estos hallazgos y la incidencia de la hepatitis A notificada en este corregimiento, se ofreció apoyo técnico para la cloración, y se llevaron a cabo actividades educativas con la comunidad haciendo énfasis en el control y la prevención de la enfermedad.

Durante el periodo de estudio, se notificaron 13 casos de hepatitis A en seis de los nueve municipios (cuadro 4). Durante las semanas del primer muestreo se notificaron casos en las poblaciones de estudio de Puerto Berrío, Girardota, Arboletes, Frontino, San Pedro de los Milagros y Zaragoza, y en los últimos cuatro mencionados se detectó el HAV en muestras ambientales. En el segundo muestreo, se notificaron dos casos en el municipio de Frontino de muestras de agua residual positivas para la detección del genoma viral. En el tercer muestreo se notificó un único caso de hepatitis A en el municipio de Zaragoza, aunque durante este lapso no se obtuvo ninguna muestra de agua positiva para la detección del genoma del HAV.

Si bien no fue posible establecer una relación entre los resultados obtenidos en las muestras de agua y los casos reportados en el Sivigila, los hallazgos coincidieron con estos en cuatro municipios, y unos y otros registraron una tendencia a la disminución.

La detección de partículas virales en las muestras ambientales depende en gran medida de la eficiencia de la técnica utilizada para establecer la concentración de partículas virales, como son la floculación con leche descremada, la ultrafiltración, la liofilización y la ultracentrifugación, entre otras 
Cuadro 4. Casos de hepatitis A notificados durante el período de estudio

\begin{tabular}{|c|c|c|c|}
\hline \multirow[t]{2}{*}{ Municipio } & \multicolumn{3}{|c|}{ Número de casos de hepatitis A reportados en el Sivigila } \\
\hline & $\begin{array}{c}\text { Semana } 48 \text { de } 2012 \text { a } \\
\text { semana } 22 \text { de } 2013 \\
\left(1^{\text {er }} \text { muestreo }\right)\end{array}$ & $\begin{array}{c}\text { Semana } 36 \text { a semana } \\
48 \text { de } 2013 \\
\left(2^{\text {do }} \text { muestreo }\right)\end{array}$ & $\begin{array}{c}\text { Semana } 49 \text { de } 2013 \text { a } \\
\text { semana } 18 \text { de } 2014 \\
\left(3^{\text {er }} \text { muestreo }\right)\end{array}$ \\
\hline Girardota (vereda San Andrés) & 4 & 0 & 0 \\
\hline San Pedro de los Milagros & 1 & 0 & 0 \\
\hline Venecia & $0^{*}$ & 0 & 0 \\
\hline Granada & 0 & 0 & 0 \\
\hline Cisneros & 0 & 0 & 0 \\
\hline Arboletes & $1^{*}$ & 0 & 0 \\
\hline Zaragoza & $1^{*}$ & 0 & 1 \\
\hline Frontino & 1 & $2^{*}$ & 0 \\
\hline Corregimiento Nutibara (Frontino) & $0^{\dagger}$ & 0 & 0 \\
\hline Puerto Berrío & $2^{\dagger}$ & 0 & 0 \\
\hline Total & 10 & 2 & 1 \\
\hline
\end{tabular}

(33-35,37-39,47). En el 2013, Calgua, et al. (38), publicaron un estudio en el que se registraron diferencias en el rendimiento de la técnica al medir el porcentaje de recuperación viral $(38,47)$. La técnica de floculación con leche descremada demostró ser más eficiente y conveniente en cuanto a su costo-efectividad y el tiempo de procesamiento de la muestra (38). Dada la naturaleza del agua residual, no es recomendable concentrar las muestras mediante técnicas que utilicen filtros o membranas antes de su tratamiento, ya que los virus pueden perderse junto con la materia orgánica previamente filtrada, lo cual disminuye el porcentaje de recuperación.

En el presente estudio las muestras de la fuente de abastecimiento de los acueductos municipales se concentraron por filtración y ultrafiltración tangencial, una técnica ya estandarizada que se emplea en el Instituto Nacional de Salud para la vigilancia de la calidad de agua para consumo humano $(16,29,33,38)$. Para las muestras de aguas residuales, se utilizaron dos metodologías (la de polietilenglicol y la floculación con leche), con el fin de incrementar la probabilidad de detectar el genoma del HAV.

Con base en los resultados obtenidos, no se observó ninguna diferencia entre estas técnicas, aunque cabe resaltar que, dado el número de muestras analizadas, las condiciones de pluviosidad y la ausencia de una prueba de referencia, no fue posible llevar a cabo los análisis estadísticos adecuados para hacer inferencias sobre la eficiencia de los protocolos utilizados. Aun así, se observaron algunas ventajas de la técnica de floculación con leche descremada frente a la de polietilenglicol en cuanto al volumen de la muestra inicial, el tiempo total de procesamiento de la muestra y los costos de los reactivos, como lo habían descrito previamente Calgua, et al. (38).

Por otra parte, no se puede descartar que las técnicas utilizadas en el segundo y el tercer muestreos fueran menos eficientes que la de concentración de partículas virales del primer muestreo. Debe señalarse que la técnica de polietilenglicol fue empleada en los tres muestreos; sin embargo, el protocolo para el segundo y el tercer muestreo difirió del primero en el control del pH y en la relación de los gramos de sedimento y los volúmenes utilizados.

En cuanto a las condiciones de pluviosidad, las lluvias pueden tener dos efectos sobre las corrientes de agua. En el caso de las fuentes de abastecimiento de los acueductos, cuando ocurren cambios drásticos en la precipitación pluvial, es decir, en la transición de verano (época seca) a invierno, el agua lluvia tiene un efecto de "lavado" en la cuenca de la quebrada, lo que causa la remoción del material orgánico que es transportado al cauce principal y puede producir un aumento en las cargas de contaminación.

Por el contrario, una vez iniciada la época de lluvias, con la cuenca lavada por las primeras precipitaciones, se presenta un fenómeno de dilución de los contaminantes en los cuerpos de agua. En el caso de las aguas residuales, las 
fuertes precipitaciones diluyen la materia orgánica presente en los efluentes cloacales. Este hecho se relaciona con el tipo de alcantarillado combinado de aguas residuales y aguas lluvias que se utiliza en el país. En época seca la materia orgánica y los contaminantes tienden a concentrarse en los sistemas de alcantarillado, ya que no ocurre la dilución por aguas lluvias.

Estos efectos se evidenciaron durante los muestreos: cuando había llovido antes de la fecha de la toma de muestras, las muestras de agua residual se notaban diluidas con respecto a las tomadas con anterioridad, lo cual se vio reflejado en la aplicación de los protocolos de concentración dado que las partículas virales se asocian con la materia orgánica presente en el agua; pero, como ya se mencionó, no fue posible determinar con precisión de qué manera estas variables afectaron la detección del genoma viral del HAV.

En el análisis filogenético se identificó el subgenotipo IA del HAV en las muestras recolectadas en Arboletes, Venecia, Zaragoza y Puerto Berrío. En el caso de las muestras recolectadas en el municipio de Frontino (corregimiento de Nutibara y cabecera municipal) no fue posible identificar las secuencias, probablemente por la baja concentración del ARN viral y la presencia de posibles inhibidores de la PCR con transcripción inversa en la muestra.

Según los resultados que se muestran en la figura 2, las secuencias de Venecia, Zaragoza y Puerto Berrío son evolutivamente más cercanas a los aislamientos identificados en Alemania y Argentina, mientras que la secuencia de la muestra recolectada en el municipio de Arboletes está más estrechamente relacionada con aislamientos de China, Japón y México. Esto podría sugerir la circulación de dos variantes del HAV en Colombia, pero, en la construcción de la base de datos de la filogenia no fue posible incluir más secuencias de estudios practicados en Latinoamérica, pues algunas de estas secuencias aún no han sido publicadas en GenBank o corresponden a la amplificación de otras regiones del genoma del VHA.

En Latinoamérica, se ha evidenciado previamente la circulación del HAV en muestras ambientales. En 2010, Betancourt, et al., determinaron la presencia del HAV en una corriente altamente contaminada del área urbana de Caracas, Venezuela. Los resultados indicaron la circulación de cepas de HAV, subgenotipo IA, estrechamente relacionadas con cepas aisladas de muestras de pacientes con diagnóstico de hepatitis A en la región (14). Prado, et al., estudiaron en 2012 muestras de agua residual del área urbana de Río de Janeiro, Brasil, y encontraron 14 muestras (58\%) positivas para HAV, de las cuales cuatro correspondían al subgenotipo IA (12). Igualmente, en Argentina, en 2014, Yáñez, et al., detectaron el genoma del HAV en $20,8 \%(5 / 24)$ de las muestras de agua residual y en $16,1 \%(5 / 31)$ de las muestras de río de la ciudad de Córdoba. El subgenotipo IA fue identificado en tres de las muestras positivas de agua residual (15). En Colombia, Sánchez, et al., identificaron recientemente el subgenotipo IA del HAV en muestras de suero y agua remitidas al Instituto Nacional de Salud entre 2008 y 2012, procedentes de ocho departamentos del país. Las secuencias obtenidas a partir de las muestras de suero y agua recolectadas durante el brote de la hepatitis en el departamento de Putumayo presentaron $98 \%$ de identidad en los nucleótidos con la cepa S79s reportada en Venezuela, Io cual sugiere su circulación en la región (16). Cabe resaltar que las secuencias del estudio en mención no se incluyeron en el analisis filogénetico presentado en la figura 2 debido a que no están disponibles en GenBank.

En el presente estudio el genoma del HAV se detectó con menor frecuencia que en los estudios mencionados, lo cual puede deberse a varios factores: primero, las diferencias de los estudios en grandes urbes y aquellas localidades con menos población usuaria de las fuentes de agua. Es de esperar que exista una relación directamente proporcional entre el número de habitantes y la contaminación microbiológica de los respectivos efluentes cloacales. Segundo, estos resultados también se pueden relacionar con la variabilidad de la región genómica VP3-VP1 amplificada por la PCR con transcripción inversa utilizada en el presente estudio y en el de Sánchez, et al. (16). La estrategia de amplificación en los estudios con muestras ambientales consiste en una PCR con transcripción inversa o en una anidada de la región 5'NCR del genoma de HAV, con una variabilidad de nucleó-tidos entre genotipos de menos de 5 \% comparada con 15 a $20 \%$ de la región VP3VP1. La estrategia de amplificación utilizada en el presente estudio permitió la identificación de las cepas presentes en las muestras ambientales, sin embargo, la sensibilidad de la técnica puede haber repercutido en el número de muestras positivas. Cabe anotar que la estrategia de amplificación utilizada en este estudio está validada tanto para 
el diagnóstico como para el análisis de muestras ambientales por el laboratorio de referencia en virología del Instituto Nacional de Salud.

Los resultados obtenidos en este estudio son de interés para las autoridades sanitarias y ambientales a nivel local, pues permiten complementar la información disponible para aportar al diseño de las políticas en salud pública relacionadas con la calidad del agua para consumo humano, así como con el manejo de desechos y la educación ambiental en las comunidades orientada a proteger y conservar los recursos naturales.

Además, la metodología utilizada puede aplicarse en los laboratorios de salud pública del país y contribuir, así, a la generación de nueva información sobre la circulación de los genotipos del HAV en muestras ambientales, lo cual es de gran utilidad para la comunidad científica nacional e internacional. Deben hacerse estudios adicionales para caracterizar las cepas que circulan en Antioquia y en otras áreas del país, y establecer su relación con las de países de la región.

\section{Conflicto de intereses}

Los autores declaran no tener conflicto de intereses.

\section{Financiación}

Este proyecto fue financiado por el Departamento Administrativo de Ciencia, Tecnología e Innovación, Colciencias (111554531673) y la Vicerrectoría de Investigación de la Universidad de Antioquia (Proyecto de sostenibilidad).

\section{Agradecimientos}

A las autoridades sanitarias, al personal de los acueductos y a las juntas de acción comunal de cada municipio, por su colaboración en la realización de este estudio.

\section{Referencias}

1. Knipe D, Howley P. Fields Virology. Sixth edition. Philadelphia: Lippincott Williams \& Wilkins; 2013. p. 551-81.

2. Provost PJ, Hilleman MR. Propagation of human hepatitis A virus in cell culture in vitro. Exp Biol Med. 1979;160:21321. http://dx.doi.org/10.3181/00379727-160-40422

3. Feng Z, Hensley L, McKnight KL, Hu F, Madden V, Ping $\mathbf{L}$, et al. A pathogenic picornavirus acquires an envelope by hijacking cellular membranes. Nature. 2013;496:367-71. http://dx.doi.org/10.1038/nature12029

4. Robertson BH, Jansen RW, Khanna B, Totsuka A, Nainan OV, Siegl G, et al. Genetic relatedness of hepatitis A virus strains recovered from different geographical regions. J Gen Virol. 1992;73:1365-77. http://dx.doi.org/10. 1099/0022-1317-73-6-1365
5. Cristina J, Costa-Mattioli M. Genetic variability and molecular evolution of hepatitis A virus. Virus Res. 2007; 127:151-7. http://dx.doi.org/10.1016/j.virusres.2007.01.005

6. Aguirre S, Malirat V, Scodeller E, Mattion N. First fulllength genomic sequence of a hepatitis $A$ virus isolated in Argentina shows recombination between subgenotypes IA and IB. Virus Res. 2011;155:316-24. http://dx.doi. org/10.1016/j.virusres.2010.10.030

7. Joshi MS, Walimbe AM, Chitambar SD. Evaluation of genomic regions of hepatitis A virus for phylogenetic analysis: Suitability of the $2 \mathrm{C}$ region for genotyping. J Virol Methods. 2008;153:36-42. http://dx.doi.org/10.1016/j. jviromet.2008.06.014

8. Báez-Triana PA, Navas-Navas MC. Infección por el virus de la hepatitis A: epidemiología y diversidad génica. latreia. 2015;28:157-69. http://dx.doi.org/10.17533/udea.iatreia. v28n2a06

9. Nainan OV, Xia G, Vaughan G, Margolis HS. Diagnosis of hepatitis A virus infection: A molecular approach. Clin Microbiol Rev. 2006;19:63-79. http://dx.doi.org/10.1128/ cmr.19.1.63-79.2006

10. Theamboonlers A, Abe K, Thongmee C, Poovorawan Y. Complete coding sequence and molecular analysis of hepatitis A virus from a chimpanzee with fulminant hepatitis. J Med Primatol. 2012;41:11-7. http://dx.doi.org/10.1111/ j.1600-0684.2011.00515.x

11. Deinhardt F, Holmes AW, Capps RB, Popper H. Studies on the transmission of human viral hepatitis to marmoset monkeys. I. Transmission of disease, serial passages, and description of liver lesions. J Exp Med. 1967;125:673-88. http://dx.doi.org/10.1084/jem.125.4.673

12. Sulbarán Y, Gutiérrez CR, Márquez B, Rojas D, Sánchez D, Navas $\mathbf{J}$, et al. Hepatitis A virus genetic diversity in Venezuela: Exclusive circulation of subgenotype IA and evidence of quasispecies distribution in the isolates. $J$ Med Virol. 2010;82:1829-34. http://dx.doi.org/10.1002/jmv.21856

13. Prado T, Fumian TM, Miagostovich MP, Gaspar AM. Monitoring the hepatitis $A$ virus in urban wastewater from Rio de Janeiro, Brazil. Trans R Soc Trop Med Hyg. 2012; 106:104-9. http://dx.doi.org/10.1016/j.trstmh.2011.10.005

14. Betancourt WQ, Querales L, Sulbarán YF, RodríguezDíaz J, Caraballo L, Pujol FH. Molecular characterization of sewage-borne pathogens and detection of sewage markers in an urban stream in Caracas, Venezuela. Appl Environ Microbiol. 2010;76:2023-6. http://dx.doi.org/10.1128/aem. 02752-09

15. Yáñez LA, Lucero NS, Barril PA, Díaz $M$ de $P$, Tenaglia MM, Spinsanti LI, et al. Evidence of hepatitis A virus circulation in central Argentina: Seroprevalence and environmental surveillance. J Clin Virol. 2014;59:38-43. http://dx.doi.org/10.1016/j.jcv.2013.11.005

16. Sánchez J, Villamil L-T, Rodríguez J, Rincón M, Méndez J, Sánchez C, et al. Genotipos del virus de hepatitis A circulantes en Colombia, 2008-2012. Hechos Microbiológicos. 2013;4:94.

17. Cuthbert JA. Hepatitis A: Old and new. Clin Microbiol Rev. 2001;14:38-58. http://dx.doi.org/10.1128/cmr.14.1.3858.2001 
18. Organización Mundial de la Salud. Hepatitis A. Nota descriptiva N. ${ }^{\circ} 328$. Fecha de consulta: 1 de junio de 2015. Disponible en: http://www.who.int/mediacentre/factsheets/ fs328/es/

19. Franco E, Meleleo C, Serino L, Sorbara D, Zaratti L. Hepatitis A: Epidemiology and prevention in developing countries. World J Hepatol. 2012;4:68-73. http://dx.doi. org/10.4254/wjh.v4.i3.68

20. Havelaar AH, Kirk MD, Torgerson PR, Gibb HJ, Hald T, Lake RJ, et al. World Health Organization global estimates and regional comparisons of the burden of foodborne disease in 2010. PLoS Med. 2015;12:e1001923. http://dx. doi.org/10.1371/journal.pmed.1001923

21. Jacobsen $\mathbf{K H}$, Wiersma ST. Hepatitis A virus seroprevalence by age and world region, 1990 and 2005. Vaccine. 2010;28:6653-7. http://dx.doi.org/10.1016/j.vaccine. 2010.08.037

22. Vacchino MN. Incidence of hepatitis $A$ in Argentina after vaccination. J Viral Hepat. 2008;15:47-50. http://dx.doi. org/10.1111/j.1365-2893.2008.01029.x

23. Vizzotti C, González J, Gentile A, Rearte A, Ramonet M, Cañero-Velasco MC, et al. Impact of the single-dose immunization strategy against hepatitis A in Argentina. Pediatr Infect Dis J. 2014;33:84-8. http://dx.doi.org/10.1097/ inf.0000000000000042

24. Ximenes RA, Martelli CM, Amaku M, Sartori AM, de Soárez PC, Novaes HM, et al. Modelling the force of infection for hepatitis $A$ in an urban population-based survey: A comparison of transmission patterns in Brazilian macro-regions. PLoS ONE. 2014;9:e94622. http://dx.doi. org/10.1371\%2Fjournal.pone.0094622

25. Ministerio de Salud y Protección Social. Lineamiento estratégico para la introducción de la vacuna contra la hepatitis $\mathrm{A}$ en el esquema del Programa Ampliado de Inmunizaciones - PAl. Colombia 2013. Fecha de consulta: 13 de julio de 2015. Disponible en: https://www. minsalud.gov.co/Documentos\%20y\%20Publicaciones/ Lineamientos\%20estrat\%C3\%A9gicos\%20para\%20 la\%20Introducci\%C3\%B3n\%20de\%20la\%20vacuna\%20 contra\%20la\%20Hepatitis\%20A.pdf

26. Instituto Nacional de Salud. Informe del evento hepatitis A hasta el periodo epidemiológico XIII, Colombia, 2014. Fecha de consulta: 15 de junio de 2015. Disponible en: http:// www.ins.gov.co/lineas-de-accion/Subdireccion-Vigilancia/ Informe\%20de\%20Evento\%20Epidemiolgico/Hepatitis\%20 A\%202014.pdf

27. Instituto Nacional de Salud. Informe del evento hepatitis A hasta el periodo epidemiológico XII, Colombia, 2015. Fecha de consulta: 10 de febrero de 2016. Disponible en: http://www.ins.gov.co/lineas-de-accion/SubdireccionVigilancia/Informe\%20de\%20Evento\%20Epidemiolgico/ HEPATITIS\%20A\%20Periodo\%20XII\%202015.pdf

28. Instituto Nacional de Salud. Vigilancia rutinaria por evento departamental 2014. Fecha de consulta: 10 de febrero de 2016. Disponible en: http://www.ins.gov.co/lineas-de-accion/ Subdireccion-Vigilancia/sivigila/Paginas/vigilancia-rutinaria. aspx

29. Peláez-Carvajal D, Rodríguez J-A, Rocha-Hernández L, Ardila-Buitrago M, Méndez JA, Sánchez CM. Detección de virus entéricos en agua para consumo humano asociados a brotes de enfermedad diarreica aguda y hepatitis A en Colombia, 2008-2013. Hechos Microbiológicos. 2013;4:80.

30. Dirección Seccional de Salud de Antioquia. Casos e incidencia de hepatitis A por subregión y municipio de Antioquia 2000-2012. Otras enfermedades en la región 2000 a 2012. Fecha de consulta: 20 de marzo de 2015. Disponible en: http://www.dssa.gov.co/index.php/ estadisticas/eventos-en-salud-publica?start $=4$

31. Secretaría de Salud y Protección Social de Frontino. Casos presentados de hepatitis $A$ en el municipio de Frontino durante los años 2011, 2012 y 2013. Frontino, Antioquia: Secretaría de Salud y Protección Social; 2014.

32. Secretaría Seccional de Salud y Protección Social de Antioquia. Población total según zona por subregiones y municipios. Antioquia 2009. Fecha de consulta: 2 de julio de 2015. Disponible en: https://www.dssa.gov.co/index.php/ estadisticas/poblacion/item/66-poblacion-2009

33. Peláez D, Rodríguez JA, Rocha EL, Rey GJ. Estandarización de un método de concentración y detección de virus entéricos en aguas de consumo. Biomédica. 2010;30:27686. http://dx.doi.org/10.7705/biomedica.v30i2.191

34. Sobsey MD, Oglesbee SE, Wait DA. Evaluation of methods for concentrating hepatitis $A$ virus from drinking water. Appl Environ Microbiol. 1985;50:1457-63.

35. González MM, Sarmiento L, Castaño JC, Giraldo AM. Detección de poliovirus en aguas residuales de Armenia, Colombia. Rev Salud Pública (Bogotá). 2006;8(Supl.1):1326. http://dx.doi.org/10.1590/S0124-00642006000400002

36. Martínez-Wassaf MG, Pisano MB, Barril PA, Elbarcha OC, Pinto MA, Mendes de Oliveira J, et al. First detection of hepatitis $E$ virus in Central Argentina: Environmental and serological survey. J Clin Virol. 2014;61:334-9. http://dx.doi. org/10.1016/j.jcv.2014.08.016

37. Calgua B, Mengewein A, Grunert A, Bofill-Mas S, Clemente-Casares P, Hundesa A, et al. Development and application of a one-step low cost procedure to concentrate viruses from seawater samples. J Virol Methods. 2008;153: 79-83. http://dx.doi.org/10.1016/j.jviromet.2008.08.003

38. Calgua B, Rodríguez-Manzano J, Hundesa A, Suñen E, Calvo M, Bofill-Mas S, et al. New methods for the concentration of viruses from urban sewage using quantitative PCR. J Virol Methods. 2013;187:215-21. http:// dx.doi.org/10.1016/j.jviromet.2012.10.012

39. Schwab KJ, De León R, Sobsey MD. Concentration and purification of beef extract mock eluates from water samples for the detection of enteroviruses, hepatitis A virus, and Norwalk virus by reverse transcription-PCR. Appl Environ Microbiol. 1995;61:531-7.

40. Mitsui T, Tsukamoto Y, Hirose A, Suzuki S, Yamazaki C, Masuko $\mathrm{K}$, et al. Distinct changing profiles of hepatitis A and $E$ virus infection among patients with acute hepatitis, patients on maintenance hemodialysis and healthy individuals in Japan. J Med Virol. 2006;78:1015-24. http://dx.doi. org/10.1002/jmv.20657

41. Ministerio de la Protección Social. Decreto 1575 de 2007. Fecha de consulta: 10 de febrero de 2016. Disponible en: https://www.minambiente.gov.co/images/normativa/decretos/ 2007/dec_1775_2007.pdf 
42. Ministerio de Protección Social, Ministerio de Ambiente, Vivienda y Desarrollo Territorial. Resolución 2115 de 2007. Fecha de consulta: 10 de febrero de 2016. Disponible en: http://www.ins.gov.co/tramites-y-servicios/programasde-calidad/Documents/resolucion $\% 202115 \% 20$ de $\% 20$ 2007,MPS-MAVDT.pdf

43. Instituto Nacional de Salud. Estado de la vigilancia de la calidad del agua para consumo humano en Colombia2013. Fecha de consulta: 12 de junio de 2015. Disponible en: http://www.ins.gov.co/sivicap/Normatividad/2014\%20 Estado\%20de\%20la\%20vigilancia\%20de\%20la \%20 calidad\%20del\%20agua\%202013.pdf?Mobile=1\&So urce $=\% 2 \mathrm{~F}$ sivicap $\% 2 \mathrm{~F}$ _layouts $\% 2 \mathrm{Fmobile} \% 2 \mathrm{Fview}$. aspx\%3FList \% 3Ddc 462e 4b- 5 de 8 - 4 a $2 f-b e 3 a-$ 08ad1c837db7\%26View\%3D0ac5f5c5-4988-442d-bc0e2c07af4f66a5\%26CurrentPage\%3D1

44. Albinana-Giménez $\mathbf{N}$, Clemente-Casares $P$, Bofill-Mas S, Hundesa A, Ribas F, Girones R. Distribution of human polyoma viruses, adenoviruses, and hepatitis $E$ virus in the environment and in a drinking-water treatment plant. Environ Sci Technol. 2006;40:7416-22. http://dx.doi.org/10. 1021/es060343i
45. Girones R, Carratalà A, Calgua B, Calvo M, RodríguezManzano J, Emerson S. Chlorine inactivation of hepatitis $E$ virus and human adenovirus 2 in water. J Water Health. 2014;12:436-42. http://dx.doi.org/10.2166/wh.2014.027

46. Widenmann A, Fischer B, Straub U, Wang C, Flehmig B, Schoenen D. Disinfection of hepatitis A virus and MS-2 coliphage in water by ultraviolet irradiation: Comparison of UV-susceptibility. Water Science and Technology. 1993;27: 335-8.

47. Villar LM, de Paula VS, Diniz-Mendes L, Lampe E, Gaspar AMC. Evaluation of methods used to concentrate and detect hepatitis $A$ virus in water samples. J Virol Methods. 2006;137:169-76. http://dx.doi.org/10.1016/j. jviromet.2006.06.008

48. Chigor V, Okoh A. Quantitative RT-PCR detection of hepatitis A virus, rotaviruses and enteroviruses in the Buffalo River and source water dams in the Eastern Cape Province of South Africa. Int J Environ Res Public Health. 2012;9:4017-32. http://dx.doi.org/10.3390/ijerph9114017 